\title{
On the Brink of Tool Use? Could Object Combinations During Foraging in a Feral Goffin's Cockatoo (Cacatua goffiniana) Result in Tool Innovations?
}

\author{
Antonio J. Osuna-Mascaró ${ }^{1 *}$ and Alice M. I. Auersperg ${ }^{2}$ \\ ${ }^{1}$ Independent scholar, Granada, Spain. \\ ${ }^{2}$ Messerli Research Institute, University of Veterinary Medicine Vienna, University of Vienna, Medical University of Vienna \\ *Corresponding author (Email: tay@ugr.es)
}

Citation - Osuna-Mascaró, A.J., \& Auersperg, A. M. I. (2018). On the brink of tool use? Could object combinations during foraging in a feral Goffin's cockatoo (Cacatua goffiniana) result in tool innovations? Animal Behavior and Cognition, 5(2), 229-234. https://doi.org/10.26451/abc.05.02.05.2018

\begin{abstract}
In captivity, the Goffin's cockatoo (Cacatua goffiniana) has shown the capacity for flexible tool use and manufacture to a degree that rivals some habitually tool using birds. Although these skills make it an important avian model species for studying physical cognition, there are no scientific records of this species using objects as tools in the wild. We hereby report a single observation of a feral individual, showing an object related foraging behavior not previously described. The bird directly and repeatedly combined plant material (alternating between stiff stalks and flimsy leaves) with the inside of a foraging source (open coconuts) in a continuous and very persistent way. Here we analyze the observation and discuss how a psychological motivation for combining objects, particularly with food sources, may represent a potential new path to the onset of avian tool use. We evaluate the possibility that this particular case may already represent tool use and highlight the theoretical importance of this finding to our present state of knowledge about the technical abilities of this species.
\end{abstract}

Keywords - Extractive foraging, Tool use, Parrot, Object combinations

Goffin's cockatoos are opportunist parrots endemic to the Tanimbar archipelago and there are introduced, self-supporting populations in Singapore (introduced around 1980; Briffett, 1984), Indonesia, and Puerto Rico. Ongoing field investigations on Tanimbar strongly suggest that they are neither specialized nor species-wide tool users (unpublished data, ongoing field work). Nevertheless, they have shown the capacity for highly flexible tool use and manufacture under laboratory conditions, rivaling the skills of habitually tool-using birds (Auersperg, Szabo, von Bayern, \& Kacelnik, 2012; Auersperg et al., 2014; Auersperg, Borasinski, Laumer, \& Kacelnik, 2016; Auersperg, Köck, Pledermann, O’Hara, \& Huber, 2017). Unlike habitually tool using birds, they do not construct complex nest cups and they lack food caching ancestry, two ecological drivers that have been proposed to have prompted the onset of tool use in birds (e.g., discussed in Kenward, Rutz, Weir, \& Kacelnik, 2006: Hansell \& Ruxton, 2008).

However, the cockatoos possess several attributes that could support the onset of tool use: they react flexibly and sensitively to small changes in their environment (e.g., Auersperg, Kacelnik, \& von Bayern, 2013; Auersperg, Laumer, \& Bugnyar, 2013; Auersperg et al., 2016, 2017), they temporarily control feeding impulses (Auersperg, Laumer, \& Bugnyar, 2013), they use extractive foraging in the wild (opening various hard shelled fruits and even digging up cassava roots; unpublished data) and establish 
complex non-functional relationships between inedible objects during object-play at similar rates as toolusing New Caledonian crows (Auersperg et al., 2015).

The first incident of cockatoo tool manufacture in a lab occurred spontaneously outside of an experimental context (Auersperg et al., 2012), and captive animals tend to show a broader range of toolusing behaviors than their wild counterparts (Haslam, 2013). There are no scientific records of these birds using tools in the wild to date. Here, we analyze observations of a feral Goffin's cockatoo in Singapore combining inedible objects with the inside of a foraging source during active extractive foraging.

\section{Methods}

On the August 5, 2016, a cockatoo (eye ring/body size suggest it was an adult male) was spotted in Sentosa Waterfront, South of Singapore, foraging on three green coconuts through holes in their shells. During one hour, with a single break of ten minutes, he fed from the coconuts while consecutively combining two different plant parts of the same tree with the inside of the fruits; one type of material was stiff, stick-like stalks (male flower stalks), and the other flimsy pieces of leaf. The coconut was likely less than 9-10 months old, and at that point, its inside would not have been completely solid. Although we recently learned that coconuts opened by Goffin's cockatoos on Tanimbar have similar features (unpublished observations), the opening could also have been created by a highly common plantain squirrel (Callosciurus notatus).

The Bird Ecology Study Group (BesGroup.org) of the Nature Society (Singapore) provided us with seven videos (24 fps, total $19 \mathrm{hr} 28 \mathrm{~min}$ ), recorded by Ang Siew Siew (see Movies $\underline{\text { S1, }} \underline{\mathrm{S} 2}, \underline{\mathrm{S}} 4, \underline{\mathrm{S}} 6$ and $\underline{\mathrm{S} 7}$ ). All seven clips belong to the same observation. With one single exception, in all clips, the focal bird was interacting with the same coconut. In four of the videos, the bird used objects in combination

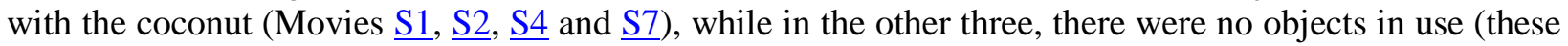
were included in the analysis because they belonged to the same observation). We analyzed the video with a coding scheme of 23 actions/events and seven modifiers separated in three categories (target, coconut area and movement), recording: head position relative to the coconut, object interaction (biting and taking), body and object readjustments, visible use of strength, part of the hole and fruit area targeted. All applicable international, national, and/or institutional guidelines for the care and use of animals were followed. No specific permissions were required for this observational and noninvasive study. A significant part of the data (Movie $\underline{\mathrm{S} 1} ; 8 \mathrm{~min}$ ) was doubly coded by a second rater. Inter-observer reliability was strong (Cohen's Kappa value for action evens $=.92$, for coconut area $=.89$; for target $=$ $.94)$.

\section{Results}

After coding 324 events within 19:28 min (AOM see authors), we found 26 stalk-coconut combinations (using nine different stalks), ten leaf-coconut combinations (four different ripped pieces of leaf) and one combination of an unidentified object with the coconut. There were 80 interactions with the beak and the coconut's hole; 27 of them pulling fibers off the open hole (using strong pulling movements with the entire body), 23 insertions of the beak towards the white meat from inside (controlled insertion of the beak without strong movements), 17 bitings of the hole used as a control for body position (biting the coconut's hole while changing the position of the legs) and 13 obscured. All objects were held on the beak while removing fibers from the open hole of the coconut (with one single exception of a change in body position while biting the coconut with a leaf on the beak).

Stalks and leaf fragments were broken off from the area surrounding the targeted coconut; only a few body readjustments were required to reach each leaf and stalk. Almost all object combinations with the coconut targeted the 'bottom' part of the fruit's opening rather than the 'top' (Stalk: bottom 21, top 0, obscured 5; Leaf: bottom 8, top 2, obscured 0; undetermined object: bottom 1, top 0, obscured 0) while the beak-only interactions with the coconut seemed to depend on the goal: biting the white meat off the inside was usually constricted to the top's inside area, while pulling fibers of the hole happened more on 
the bottom (biting insides: bottom 2, top 18, obscured 4; biting fibers of the open hole: bottom 17, top 5, obscured 1; biting for control position: bottom 7, top 8, obscured 1). Some leaves were readjusted but less frequently than stalks, and in two occasions, were chewed (folded inside the beak) before being applied to the fruit (leaves readjustments 2, leaves folded 2; stalk readjustments 18). Stalks were always employed in the same manner: they were gripped with the beak at the thicker end, which was then pressed into the coconut's opening by that end (see Figure 1). Pulling fibers off the open hole was done with or without stalks and leaves, but when an object was applied, more coconut pieces were seen falling down (19 with object, two without).

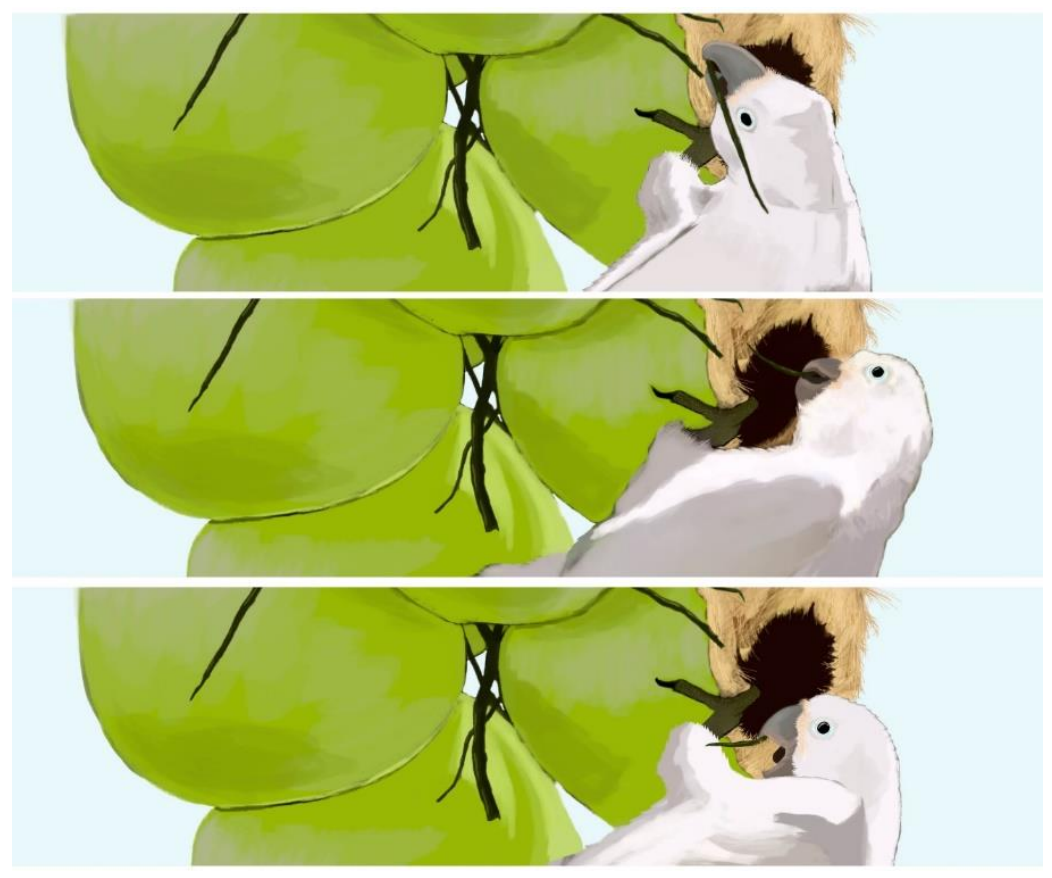

Figure 1. Typical stalk-fruit combination. Top to bottom: A piece of flower stalk is bitten off nearby the feeding site; the stalk is gripped at the thick end and combined with the bottom part of the coconut.

When the cockatoo inserted the beak into the coconut, the movement patterns strongly differed from biting the fibers off the opening. Biting inside was accompanied by stretching the neck and body

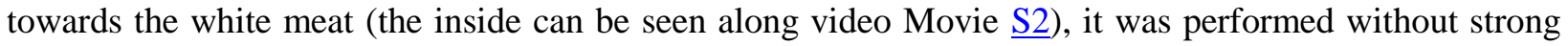
movements, it was usually followed by a beak position of tip to tip (upper and lower tips of the beak touching, as holding something), munching movements of beak/tongue (4 clear events) and, in one case, a white piece of coconut meat was extracted (Movie $\underline{\mathrm{S} 7}$ at 1:05).

\section{Discussion}

Here, we provide the first report of object combinations in an extractive foraging context by a free-ranging Goffin's cockatoo. While we previously observed object combinations by free-ranging conspecifics on the Tanimbar islands (unpublished data), we have so far not been able to record object combinations that were aimed directly against an extractive foraging source. The behavior does thus, not seem to be a habitual trait that is widely expressed across populations.

Notably, the objects are not combined with another inedible item but directly with a food source while the bird is actively feeding. This is important because play usually occurs in a satiated context (e.g., Bateson \& Martin, 2013). The behavior is thus unlikely simply a case of combinatory object play as previously reported in captive Goffin's cockatoos (Auersperg et al., 2015) but could be part of a foraging 
routine. This is surprising as, while pre-existing behavioral patterns are believed to have played a role in the onset of tool use (Alcock, 1972), those that are context-specific, such as object play, are believed to be hard to transfer to foraging contexts (Hunt, Gray, \& Taylor, 2013).

We were able to record three kinds of beak-coconut interactions within the videos: pulling fibers from the opening (with or without pressing objects against it), using the opening as a support to change the body position, and inserting the head (most likely to feed from inside the fruit). Similar to the first observation of cockatoo tool use in Vienna (Auersperg et al., 2012), the combinatory behavior was shown by only a single individual despite other conspecifics feeding nearby, suggesting the focal bird to possibly be an individual innovator.

Cockatoos from the endemic population on Tanimbar occasionally feed and even open coconuts (personal communication with our field team). Nevertheless, it has been suggested that moving into a novel, harsher environment may facilitate tool use-like behaviors (Alcock, 1972). Although Singapore does not seem to lack resources, it has more bird species than Tanimbar (including two other cockatoo species; see avibase.com) and the Goffins are likely to face more competition than in their original habitat.

In the video, the combinations were frequent and directed specifically at the fibers at the opening: the bird clearly held an object in $31 \%$ of the times that he interacted with the hole in the nut (49\% of the interactions with the opening). Moreover, while combinations of the fruit with stiff stalks were repeated multiple times, combinations of the fruit with flimsy leaves were less common (26 vs. 10). Leaves seemed to be easier to reach than stalks and more abundant. Yet they could simply be lost earlier because they were destroyed faster. Alternatively, the stalks may be more advantageous in this foraging situation. It is likely that the stalks and leaves were helpful while tearing apart the fibers to enlarge the opening and acquiring access to the jelly-like liquid of the young fruit: Although half of the interactions with the opening were without objects, in those interactions where fibers were pulled in combination with a stalk or a leaf many more small pieces of coconut were visible falling down. Leaves could serve as a wedge to support the bird's grip on the fruit as has been described in others parrots and cockatoos (Borsari \& Ottoni, 2005; Wallace, 1890).

Stalks were always inserted with the thicker part first and held by the bird close to this 'working end' followed by strong lateral body movements. While the thick part might serve as a better tool to pull fibers as a wedge, this could be accidental. For example, the favorable orientation of barbed pandanus tools by New Caledonian crows turned out to be a side effect of their manufacturing technique (Holzhaider, Hunt, Campbell, \& Gray, 2008). The cockatoo may have simply been gripping the thicker end because it marks the breaking point from the plant.

Due the nature of this particular observation, at this point, the benefits of using these objects as wedges have to remain speculative. Almost every time that we can see pieces falling down (89\%), there is an object in use, but we do not know if the use of these objects is truly helpful for the bird or just a vain attempt to further open the hole of the coconut. Nevertheless, importantly, intense combinations of objects with food sources as described in this case combined with very fast operant and social learning abilities, flexible extractive foraging and the capacity for tool use in captivity (Auersperg et al., 2012, 2016; Auersperg, Laumer, \& Bugnyar, 2013; Auersperg, Kacelnik, \& von Bayern, 2013) do generally constitute a scenario that could easily prompt the innovation and spread of tool use in a foraging context if the outcome of such a combination did prove advantageous.

Birds have largely been argued to develop tool use by modification of existing ecological specializations such as nest building from twigs or food caching in cavities (Alcock, 1972; Hansell \& Ruxton, 2008; Kenward et al., 2011). This species reaches levels of tools use in the lab that strongly rival even the most specialized non-human tool users (Auersperg el al., 2012, 2014, 2016, 2017) but is not a habitual tool user, not a nest builder and not a food cacher. Yet, they recurrently combine environmental objects during play and exploration (Auersperg et al., 2015). We argue that a strong psychological motivation to combine objects could change from play into foraging behavior if the combination of an object with another accidentally provided profits to the actor: if the outcome of such a combination unexpectedly allowed or facilitated access to a foraging source it could quickly become reinforced, 
refined and turn into tool use or simply enhance the inclusion of other object combinations into foraging routines. This could potentially represent a new path to the onset of avian tool use.

What we can conclude from this and previous lab observations (Auersperg et al., 2012, 2015) is that the Goffin's cockatoo seem to have their capacity to develop tool use and manufacture from their adaptive flexibility and most likely a propensity to explore different variants of object combinations. Due to the consistency of this individual along the videos analyzed and their highly flexible tool use and manufacture under laboratory conditions, we hypothesize that, in this species, tool use could spontaneously appear in individuals but has not spread across populations, making this a species that could be in a tipping state between flexible extractive foraging and tool use. While this is a highly important starting point, future fieldwork on this species will bring further insights into their opportunistic foraging techniques and shed further light on these findings.

\section{Acknowledgements}

The Bird Ecology Study Group of the Nature Society, Singapore and Ang Siew Siew for providing details of their observation. Alice Auersperg was funded by the FWF projects no. P29084 and P29075.

\section{References}

Alcock J. (1972). The evolution of the use of tools by feeding animals. Evolution, 26, 464-473. http://dx.doi.org/10.2307/2407020

Auersperg A. M. I., Borasinski S., Laumer I., \& Kacelnik K. (2016). Goffin's cockatoos make the same tool type from different materials. Biology Letters, 12, 20160689. http://dx.doi.org/10.1098/rsbl.2016.0689

Auersperg, A. M. I., Kacelnik, A., \& von Bayern, A. M. P. (2013). Explorative learning and functional inferences on a five-step means-means-end problem in Goffin's cockatoos (Cacatua goffini). PLoS One, 8, e68979. http://dx.doi.org/10.1371/journal.pone.0068979

Auersperg, A. M. I., Köck, C., Pledermann, A., O’Hara, M., \& Huber, L. (2017). Safekeeping of tools in Goffin's cockatoos (Cacatua goffiniana). Animal Behaviour, 128, 125-133. http://dx.doi.org/10.1016/j.anbehav.2017.04.010

Auersperg, A. M. I., Laumer, I., \& Bugnyar, T. (2013). Goffin cockatoos wait for qualitative and quantitative gains but prefer 'better' to 'more'. Biology Letters, 9, 20121092. http://dx.doi.org/10.1098/rsbl.2012.1092.

Auersperg, A. M. I., Szabo, B., von Bayern, A. M. P., \& Kacelnik, A. (2012). Spontaneous innovation of tool manufacture and use in a Goffin's cockatoo. Current Biology, 22, R903-R904. http://dx.doi.org/10.1016/j.cub.2012.09.002.

Auersperg, A. M. I., van Horik, J., Bugnyar, T., Kacelnik, K., Emery, N., \& von Bayern, A. M. P. (2015). Combinatory actions during object play in psittaciformes (Diopsittaca nobilis, Pionites melanocephala, Cacatua goffini) and corvids (Corvus corax, C. monedula, C. moneduloides). Journal of Comparative Psychology, 129, 62-71. http://dx.doi.org/10.1037/a0038314

Auersperg, A. M. I., von Bayern, A. M. P., Weber, S., Szapari, A., Bugnyar, T., \& Kacelnik, A. (2014). Social transmission of tool use in the Goffin cockatoo. Proceedings of the Royal Society, Series B, 281, 20140972. http://dx.doi.org/10.1098/rspb.2014.0972.

Bateson, P., \& Martin, P. (2013). Play, playfulness, creativity and innovation. Cambridge, UK: Cambridge University Press.

Borsari, E., \& Ottoni, E. B. (2005). Preliminary observations of tool use in captive hyacinth macaws (Anodorhynchus hyacinthinus). Animal Cognition, 8, 48-52. http://dx.doi.org/10.1007/s10071-004-0221-3

Briffett, C. (1984). Pocket checklist of the birds of Singapore. Singapore: Malayan Nature Society (Singapore branch) Bird Group Singapore.

Hansell, M., \& Ruxton, G. D. (2008). Setting tool use within the context of animal construction behaviour. Trends in Ecology and Evolution, 23, 73-78. http://dx.doi.org/10.1016/j.tree.2007.10.006.

Haslam, M. (2013). 'Captivity bias' in animal tool use and its implications for the evolution of hominin technology. Philosophical Transactions of the Royal Society B, 368, 20120421. http://dx.doi.org/10.1098/rstb.2012.0421 
Holzhaider, J. C., Hunt, G. R., Campbell, V. M., \& Gray, R. D. (2008). Do wild New Caledonian crows (Corvus moneduloides) attend to the functional properties of their tools? Animal Cognition, 11, 243-254. http://dx.doi.org/10.1007/s10071-007-0108-1

Hunt, G. R., Gray, R. D., \& Taylor, A. (2013). Why is tool use rare in animals? In C. M. Sanz, J. Call, \& C. Boesch (Eds.), Tool use in animals: Cognition and ecology (pp. 89-119). Cambridge, UK: Cambridge University Press.

Kenward, B., Rutz, C., Weir, A. A. S., \& Kacelnik, A. (2006). Development of tool use in New Caledonian crows: Inherited action patterns and social influences. Animal Behaviour, 72, 1329-1343. http://dx.doi.org/10.1016/j.anbehav.2006.04.007

Kenward, B., Schloegl, C., Rutz, C., Weir, A. A. S., Bugnyar, T., \& Kacelnik, A. (2011). On the evolutionary and ontogenetic origins of tool-oriented behaviour in New Caledonian crows (Corvus moneduloides). Biological Journal of the Linnean Society, 102, 870-877. http://dx.doi.org/10.1111/j.10958312.2011.01613.x

Wallace, A. R. (1890). The Malay archipelago. Retrieved from Wallace-online.org. 